\title{
Riverscape correlates for distribution of threatened spotfin chub Erimonax monachus in the Tennessee River Basin, USA
}

\author{
Joshuah S. Perkin ${ }^{1}$, W. Keith Gibbs ${ }^{2, *}$, Josey L. Ridgway ${ }^{3}$, S. Bradford Cook ${ }^{4}$ \\ ${ }^{1}$ Department of Wildlife and Fisheries Sciences, Texas A\&M University, College Station, TX 77843, \\ ORCID: 0000-0002-1409-2706, USA \\ ${ }^{2}$ Department of Geosciences and Natural Resources, Western Carolina University, Cullowhee, NC 28723, USA \\ ${ }^{3}$ US Geological Survey, Columbia Environmental Research Center, 4200 New Haven Road, Columbia, MO 65201, USA \\ ${ }^{4}$ Department of Biology, Tennessee Technological University, Cookeville, TN 38505, USA
}

\begin{abstract}
Globally, aquatic biodiversity is imperiled at an increasing rate, especially in diversity hotspots such as the southeastern USA. The spotfin chub Erimonax monachus is a federally threatened minnow with a disjunct distribution resulting from numerous impoundments on the Tennessee River and its tributaries in the heart of the southeastern USA. Recovery actions required to remove federal protection for E. monachus are dependent on the establishment of additional populations within the historical range of the species, but little is known regarding macroscale habitat requirements that could guide conservation planning. We analyzed local- and networkscale watershed attributes to develop an ecological niche model (ENM) for E. monachus useful for directing conservation actions at sampled and unsampled sites across the Tennessee River Basin. We found E. monachus occurred most often in larger streams with large upstream catchment areas and minimal alteration to forested uplands, but all of these sites were in close proximity to high densities of downstream dams due to populations being restricted to large-stream habitat upstream of reservoirs. The ENM showed the highest probability of E. monachus occurrence among catchment locations with known extant populations; however, additional historical and previously unoccupied catchments showed potential for successful (re)introductions, provided that fine-scale habitats are appropriate. Our framework can be used to identify potential survey and (re)introduction sites for E. monachus as well as other rare riverine fishes and represents a method for identifying areas of high priority for conserving aquatic biodiversity.
\end{abstract}

KEY WORDS: Ecological niche model · Species restoration ' Landscape alteration · Biodiversity preservation

\section{INTRODUCTION}

Globally, biodiversity diminished over the last century in both terrestrial and aquatic realms as human domination of ecosystems increased (Vitousek et al. 1997). Aquatic fauna such as freshwater mussels, fishes, aquatic invertebrates, crayfishes, and amphibians are disproportionally at risk of imperilment compared with terrestrial organisms (Richter et al.

\footnotetext{
${ }^{*}$ Corresponding author: wgibbs@wcu.edu
}

1997, Dudgeon et al. 2006). Multiple anthropogenic factors contribute to aquatic habitat alteration and, consequently, the abundances and distributions of fauna occupying aquatic environments. These factors include habitat degradation, water pollution, over-exploitation, introduction of non-indigenous and invasive species, and impoundment and flow modification of river systems (Miller 1972, Cole \& Landers 1995, Dudgeon et al. 2006). Slowing or halting bio- 
diversity loss requires greater understanding of interactions among the multiple threats that influence organism distributions and abundances (Strayer \& Dudgeon 2010).

Stream fishes represent a well-studied but widely declining group of freshwater organisms (Closs et al. 2016). Threats to stream fish diversity are similar to other aquatic organisms, but riverine landscape alterations that cause increased sedimentation and population fragmentation are among the most widespread threats (Angermeier 1995, Warren et al. 2000, Sutherland et al. 2002). Improper or inadequate erosion control techniques have substantially increased sedimentation to streams and rivers, effectively altering local habitat templates and flow regimes that molded evolutionary adaptations of stream fishes (Lytle \& Poff 2004). Impoundment of rivers has isolated many endemic riverine fishes while completely decimating others reliant on continuously flowing systems for migratory spawning (Liermann et al. 2012, Perkin et al. 2015a). Only 42 rivers with unimpounded longitudinal lengths greater than $200 \mathrm{~km}$ remain in the conterminous USA, and less than $2 \%$ of all streams are of adequate quality to be federally protected as wild and scenic (Benke 1990). Dams and impoundments are of special concern because they directly block fish passage throughout a river network, limiting fish habitat ranges and disconnecting gene flow between meta-populations (Gido et al. 2016). In addition, impoundments disrupt ecological processes, in particular the natural discharge and thermal regime of rivers (Petts 1986, Poff et al. 1997). This is concerning because riverine fish depend on relatively natural discharge and thermal regimes to trigger spawning and sustain recruitment and survival; thus, dams can hinder the presence and timing of fish reproduction (Craven et al. 2010, Olden \& Naiman 2010, Perkin et al. 2016). Addressing declines in stream fish diversity will in part require understanding how existing or future dams influence the distribution and abundance of species (Olden 2016). Specifically, limited understanding of life history, habitat connectivity, and flow regime requirements of fishes are identified as research areas critical for improving fish diversity conservation (Cooke et al. 2012).

The southeastern USA has the highest diversity of freshwater fishes, the largest number of endemic species, and the largest number of imperiled fishes in North America (Warren \& Burr 1994, Warren et al. 2000). In fact, the southeastern USA is ranked among global hotspots for fish biodiversity (Abell et al. 2008). The Tennessee River Basin is one of the most diverse drainage basins in the USA, harboring approximately 250 species and subspecies (Starnes \& Etnier 1986). Fishes in the families Cyprinidae (minnows) and Percidae (darters) are the 2 most diverse groups in the Tennessee River Basin and are proportionally the most imperiled species (Warren \& Burr 1994). Conserving these diverse groups requires understanding the appropriate spatial scales for implementing conservation initiatives (Fausch et al. 2002, Kanno et al. 2012a), and Etnier (1997) identified medium-sized rivers as preferred habitats for many imperiled fishes in the region. Consequently, species requiring medium-sized streams can be used as sentinels to enhance our understanding of fish diversity decline (Wenger 2008). Because of the high level of diversity and relatively intact nature of the Tennessee Basin fauna, a portion of the Tennessee River was recently designated as a native fish conservation area (NFCA) (Williams et al. 2011). This designation points to the potential for the existence of other unidentified high-quality habitats in the basin that could be used to promote conservation of declining or imperiled fishes.

The spotfin chub Erimonax monachus is endemic to the Tennessee River and is associated with mediumsized rivers in disjunct populations throughout the basin (Etnier \& Starnes 1991). E. monachus is a smallbodied cyprinid that was historically extant over a wide range covering 5 states: Alabama, Georgia, North Carolina, Tennessee, and Virginia. The species was historically distributed across 4 physiographic provinces and 12 tributary systems of the Tennessee River (Jenkins \& Burkhead 1984). However, populations are fragmented by various anthropogenic barriers and are now localized to only 4 tributary systems: (1) the Little Tennessee River, North Carolina; (2) the Buffalo and (3) Emory rivers, Tennessee; and (4) the north and middle forks of the Holston River in Tennessee and Virginia (Jenkins \& Burkhead 1984). The US Fish and Wildlife Service (USFWS) now recognizes E. monachus as a threatened species under the Endangered Species Act (Federal Register 1977), and extirpations are attributed primarily to fragmentation, habitat degradation, and hydrologic alteration (Jenkins \& Burkhead 1984). However, this species has been reintroduced in several catchments with historical records and introduced in additional catchments within the Tennessee River Basin (P. Rakes, Conservation Fisheries, pers. comm.) as part of recovery efforts. E. monachus is a fractional crevice spawner characterized by females depositing eggs in gaps among large substrates several times from May through mid-August 
(Jenkins \& Burkhead 1984). It is hypothesized that fragmented access to appropriate spawning habitat is a leading factor contributing to local extirpations (Etnier \& Starnes 1993). However, each extant population appears to use fine-scale habitats according to availability, though silt-laden substrates are typically avoided (Jenkins \& Burkhead 1984, Kanno et al. $2012 \mathrm{~b}$ ). Based on the apparent plasticity of fine-scale habitat associations, broader-scale habitats might be appropriate for describing and predicting the distribution of the species.

The purpose of our study was to analyze catchment characteristics across E. monachus's historical range within the Tennessee River Basin to identify factors influencing current distribution. The primary objective of the E. monachus recovery plan is to restore viable populations to a significant portion of their historical range so they no longer require federal protection under the Endangered Species Act (USFWS 1983). Specifically, the recovery plan calls for the protection and preservation of naturally extant populations and determination of the feasibility of reestablishing populations throughout their historical range. Thus, we sought to develop an ecological niche model (ENM; Peterson \& Soberón 2012) that describes the spatial locations of high-priority habitats, both currently occupied and potentially occupied. Once developed, an ENM could be used to guide management decisions regarding the protection of extant populations and to identify segments with suitable habitat for additional reintroductions to fulfill recovery objectives for the species. We hypothesized that $E$. monachus extirpations would be correlated with habitat fragmentation, especially due to large impoundments that limit suitable habitat across the Tennessee River Basin. Because large impoundments are likely to be permanent structures on riverscapes for the foreseeable future, identifying potential reintroduction sites at previously unsampled areas represents a much-needed research endeavor for guiding progress towards conservation goals (Olden 2016).

B

\section{MATERIALS AND METHODS}

\subsection{Study area}

The Tennessee River is the largest tributary to the Ohio River, comprising $\sim 20 \%$ of the Ohio River Basin and containing $>90 \%$ of fish species found throughout the basin (White et al. 2005). The Tennessee River Basin $\left(\sim 105000 \mathrm{~km}^{2}\right)$ traverses 7 states: Alabama, Georgia, Kentucky, Mississippi, North Carolina, Tennessee, and Virginia (Fig. 1A). The headwaters begin in the mountains of southwestern Virginia, western North Carolina, and northern Georgia. Major tributaries include the Clinch, Powell, Holston, French Broad, Little Tennessee, Hiwassee, Emory, Elk, Buffalo, and Duck rivers. The con-
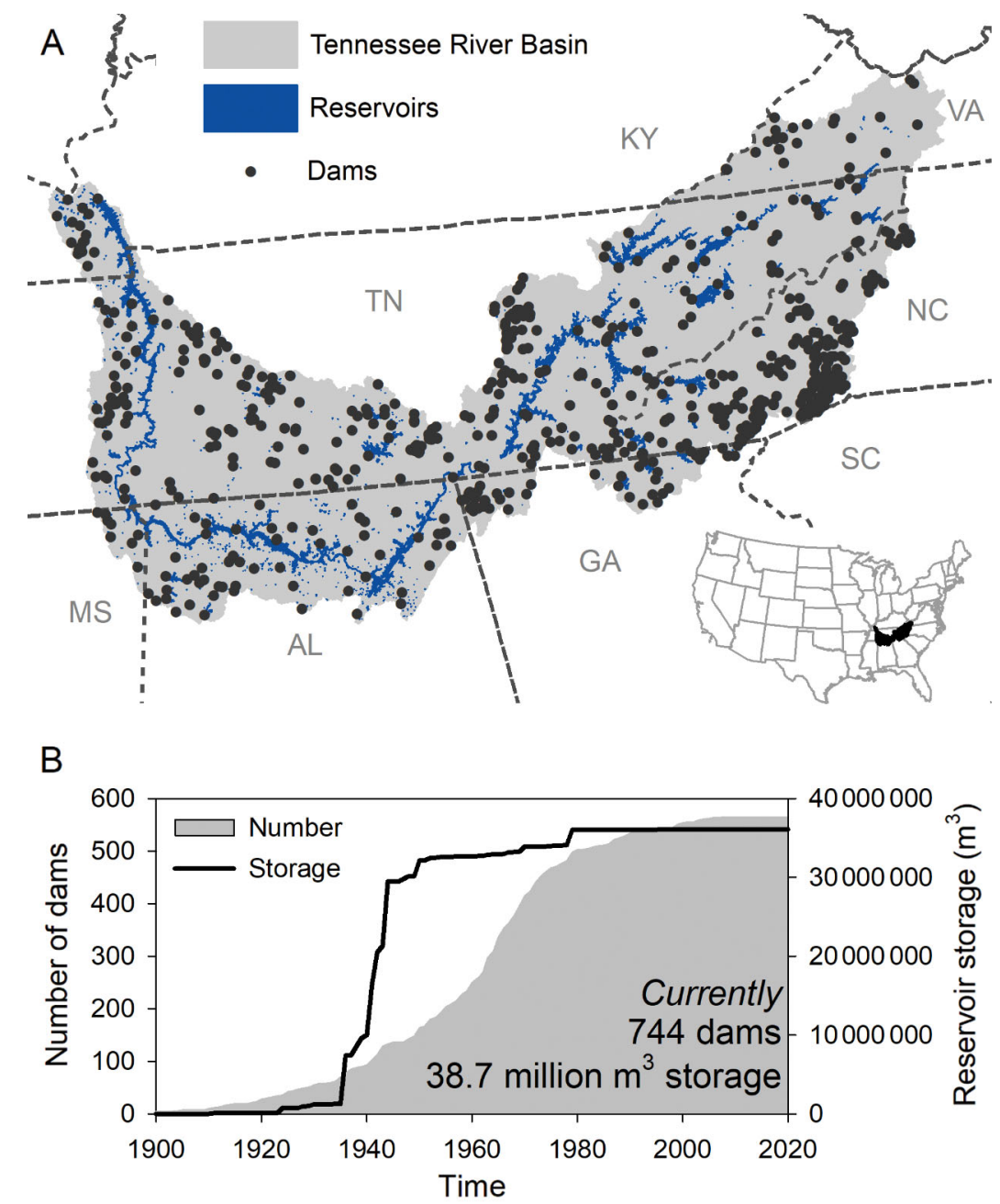

Fig. 1. (A) Tennessee River Basin in the southeastern USA illustrating extensive habitat fragmentation by dams and reservoirs. (B) Timing of dam construction increased most between 1950 and 1980 for dams that have date data, and the 744 current dams create reservoirs with a combined storage capacity $>38.7 \mathrm{~m} \mathrm{~m}^{-3}$ of water. Dams without dates were excluded from the timeline of accumulation 
fluence of the Holston and French Broad rivers forms the Tennessee River proper, which flows $\sim 1050 \mathrm{~km}$ to its confluence with the Ohio River (White et al. 2005). Although the Tennessee River Basin is large and speciose, habitat fragmentation and hydrologic alteration have negatively affected aquatic species diversity (Neves \& Angermeier 1990).

Hydrologic alteration of the Tennessee River and its tributaries began in the early 1900s for navigation, flood control, and hydroelectric power (Toplovich 2017, https://www.tva.gov/About-TVA/Our-History). Hales Bar Dam was constructed on the Tennessee River near Chattanooga, TN, between 1905 and 1913. Wilson Dam on the lower Tennessee River was finished in 1924. By the early 1930s, several other impoundments were constructed in headwater systems, including on the Cheoah, Ocoee, Toccoa, and Watauga rivers. Creation of the Tennessee Valley Authority (TVA) in 1933 resulted in rapid production of hydroelectric and navigational dams along the Tennessee River and its tributaries (Fig. 1B). Tellico Dam was completed in 1979 and was the last major reservoir created within the Tennessee River Basin. Today, the TVA operates 9 locks and dams on the main stem of the Tennessee River and 23 dams on its tributaries. Other utility companies operate hydroelectric dams on several tributaries, and 744 total dams with a collective storage capacity of $38736126 \mathrm{~m}^{3}$ are documented in the National Anthropogenic Barrier Dataset (Ostroff et al. 2013). Additionally, navigation canals have been constructed between the Tennessee and Tombigbee rivers and between the Tennessee and Cumberland rivers. Consequently, the Tennessee River basin is a highly altered and regulated system of reservoirs connected by intermittent free-flowing riverine segments (Neves \& Angermeier 1990).

Very few subcatchments within the Tennessee River Basin remain unimpounded. The Buffalo, Emory, and Sequatchie rivers are the only systems that flow unimpeded to the Tennessee River. Upper portions of the Clinch, French Broad, Holston, and Powell rivers also have substantial free-flowing segments but are impounded prior to their confluences with the Tennessee River. Several rivers, such as the Little Tennessee River, have small overflow impoundments in their upper reaches but retain large segments of free-flowing water between impoundments. Identifying large, intact catchments to promote long-term viability of native fish populations is a major goal of NFCAs (Williams et al. 2011). The Little Tennessee River was recently designated as an NFCA by the North Carolina Wildlife Federation to enhance collaboration among multiple agencies and organizations to provide sustainable catchment management practices and protect native fish, including Erimonax monachus. Several other catchments, including those harboring extant populations of $E$. monachus, meet the criteria for designation as NFCAs.

\subsection{Landscape data}

We conducted spatial analyses to relate landscape characteristics to the distribution of E. monachus. Geospatial data included 52 parameters describing natural stream gradients, stream network connectivity, catchment land use and land cover, terrestrial and aquatic landscape alterations, and habitat disturbance indices for the entire Tennessee River Basin (Table 1). These data were obtained from the US Geological Survey National Hydrography Dataset (NHD) Version 2 Plus described by McKay et al. (2012) and extension attributes developed for habitat disturbances (Esselman et al. 2011) and stream network connectivity (Cooper \& Infante 2017). We compiled land use and land cover data, landscape alteration densities, and habitat disturbance data at 2 spatial extents, local catchments and network catchments. These data were originally collected and analyzed from 2005 to 2015, which corresponds to the fish occurrence data for our analyses. Local catchments were defined as the area of land draining directly into an interconfluence stream segment (i.e. length of stream between 2 confluences), whereas network catchments included all upstream areas across multiple local catchments (see illustrations in Perkin et al. 2019). All geospatial data were linked to NHD streamlines in ArcMap 10.4.1 GIS (ESRI 2015).

\subsection{Fish occurrence data}

We confined the spatial extent of our investigation to the historical and contemporary distribution of $E$. monachus (Table 2). Extirpated populations were determined from historical records (Jenkins \& Burkhead 1984, Etnier \& Starnes 1993), and the current distribution as well as catchments where E. monachus have been successfully (re)introduced were provided by Conservation Fisheries (P. Rakes \& J. R. Shute unpubl. data). Abrams Creek represents the sole unsuccessful reintroduction to date and was included in analyses based on the species' historical 
Table 1. Predictor variables used to model distribution of Erimonax monachus. Note: In their calculation of metrics, Cooper \& Infante (2017) defined main stems as streams of similar or larger streams compared with the focal stream segment

\begin{tabular}{|c|c|}
\hline Variable & Description and units \\
\hline \multicolumn{2}{|l|}{ Natural stream gradient } \\
\hline N_AREASQKM & Catchment area of total upstream network $\left(\mathrm{km}^{2}\right)^{\mathrm{a}}$ \\
\hline L_AREASQKM & Local catchment area $\left(\mathrm{km}^{2}\right)^{\mathrm{c}}$ \\
\hline StreamOrder & Stream order (Strahler 1957) \\
\hline RunOffVC & Estimated runoff for stream segment $(\mathrm{mm})^{\mathrm{b}}$ \\
\hline SLOPE & Stream channel slope $\left(\mathrm{m} \mathrm{m}^{-1}\right)^{\mathrm{b}}$ \\
\hline TempVC & Average annual air temperature $\left({ }^{\circ} \mathrm{C} \times 100\right)^{b}$ \\
\hline MINELEVSMO & Minimum elevation of stream segment $(\mathrm{cm})^{\mathrm{b}}$ \\
\hline \multicolumn{2}{|l|}{ Network connectivity } \\
\hline DMD & Density of downstream mainstem dams (no. $\left.100 \mathrm{~km}^{-1}\right)^{\mathrm{c}}$ \\
\hline DM2D & Distance to downstream mainstem dam $(\mathrm{km})^{\mathrm{c}}$ \\
\hline DMO & Percent of open (i.e. free of dams) downstream main stem \\
\hline SMST & Segment mainstream length $(\mathrm{km})^{\mathrm{C}}$ \\
\hline STOT & Total segment network length between 2 dams $(\mathrm{km})^{\mathrm{c}}$ \\
\hline TMD & Total mainstem dam density $\left(\text { no. } 100 \mathrm{~km}^{-1}\right)^{\mathrm{c}}$ \\
\hline TM2D & Total mainstem distance between upstream and downstream dams $(\mathrm{km})^{\mathrm{c}}$ \\
\hline TMO & Total percent of open mainstem habitat $(\%)^{\mathrm{c}}$ \\
\hline UDOR & Percent of estimated annual discharge stored in upstream reservoirs $(\%)^{\mathrm{c}}$ \\
\hline UMD & Upstream mainstem dam density per mainstem length $\left(\text { no. } 100 \mathrm{~km}^{-1}\right)^{\mathrm{c}}$ \\
\hline UM2D & Distance to upstream mainstem dam $(\mathrm{km})^{\mathrm{c}}$ \\
\hline UMO & Percent of open upstream main stem $(\%)^{\mathrm{c}}$ \\
\hline UNDC & Upstream dam density $\left(\text { no. } \mathrm{km}^{-2}\right)^{\mathrm{c}}$ \\
\hline UNDR & Upstream network dam density per stream network length (no. $\left.100 \mathrm{~km}^{-1}\right)^{\mathrm{c}}$ \\
\hline USC & Total upstream reservoir storage per stream network catchment area $\left(\text { hectare-meters } \mathrm{km}^{-2}\right)^{\mathrm{c}}$ \\
\hline USR & Total upstream reservoir storage volume per stream network length (hectare-meters $\left.100 \mathrm{~km}^{-1}\right)^{\mathrm{c}}$ \\
\hline \multicolumn{2}{|l|}{ Land cover and land use } \\
\hline L_or N_CROPS & Percent crop land use in local or network catchment $(\%)^{\mathrm{a}}$ \\
\hline L_or N_PASTURE & Percent pasture land use in local or network catchment $(\%)^{\mathrm{a}}$ \\
\hline L_or N_URBANL & Percent low-intensity urban land use in local or network catchment $(\%)^{a}$ \\
\hline L_or N_URBANM & Percent medium-intensity urban land use in local or network catchment $(\%)^{\mathrm{a}}$ \\
\hline $\mathrm{L}_{-}^{-}$or N_URBANH & Percent high-intensity urban land use in local or network catchment (\%) ${ }^{\mathrm{a}}$ \\
\hline \multicolumn{2}{|c|}{ Landscape alteration density } \\
\hline L_or N_CERC_DENS & Density of Superfund National Priorities List sites within local or network catchment \\
\hline L_or N_DAMS_DENS & Density of dams in local or network catchment $\left(\text { no. } \mathrm{km}^{-2}\right)^{\mathrm{a}}$ \\
\hline L_or N_MINES_DENS & Density of mines in local or network catchment $\left(\text { no. } \mathrm{km}^{-2}\right)^{\mathrm{a}}$ \\
\hline L_or N_NPDES_DENS & $\begin{array}{l}\text { Density of National Pollutant Discharge Elimination System sites in local or network } \\
\text { catchment }\left(\text { no. } \mathrm{km}^{-2}\right)^{\mathrm{a}}\end{array}$ \\
\hline L_or N_POP_DENS & Human population density in local or network catchment (people $\left.\mathrm{km}^{-2}\right)^{\mathrm{a}}$ \\
\hline L_or N_ROAD_DENS & Density of roads in local or network catchment $\left(\text { crossings } \mathrm{km}^{-2}\right)^{\mathrm{a}}$ \\
\hline L_or N_ROAD_L_DENS & Density of road length in local or network catchment $\left(\mathrm{km} \mathrm{km}^{-2}\right)^{\mathrm{a}}$ \\
\hline L_or N_TRI_DENS & Density of toxic release inventory sites (TRI) in local or network catchment $\left(\mathrm{no} . \mathrm{km}^{-2}\right)^{\mathrm{a}}$ \\
\hline \multicolumn{2}{|l|}{ Habitat disturbance index } \\
\hline CumDistIndx & $\begin{array}{l}\text { Averaged anthropogenic disturbance index }(1=\text { highest risk of habitat degradation } \\
5={\text { lowest risk of habitat degradation })^{\mathrm{a}}}\end{array}$ \\
\hline NDistIndx & $\begin{array}{l}\text { Habitat disturbance index for upstream network }(1=\text { highest risk of habitat degradation; } \\
5=\text { lowest risk of habitat degradation })^{\mathrm{a}}\end{array}$ \\
\hline LDistIndx & 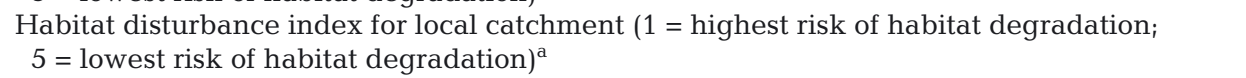 \\
\hline
\end{tabular}

distribution. We also included additional locations where the species is permitted for introductions based on Federal Register regulations (Federal Register 2002, 2005, 2007). Within this geographic area (Fig. 2A), we developed a presence-absence dataset for E. monachus using survey collections conducted by the TVA (J. Simmons, TVA, unpubl. data). Extant E. monachus and whitetail shiner Cyprinella galactura occurrences were documented by the TVA during Index of Biotic Integrity surveys between 1986 
Table 2. Variables influencing Erimonax monachus distribution for major catchments with extant, extirpated, reintroduced, and introduced E. monachus populations throughout the Tennessee River Basin, and catchments permitted for future introductions. agr: agricultural; dev: developed; (-) not present

\begin{tabular}{|c|c|c|c|c|c|c|}
\hline ID & River system & Status & State & $\begin{array}{l}\text { Total drainage } \\
\text { area }\left(\mathrm{km}^{2}\right)\end{array}$ & $\begin{array}{l}\text { Stream } \\
\text { order }\end{array}$ & $\begin{array}{l}\text { Altered land use } \\
\text { (agr/dev) (\%) }\end{array}$ \\
\hline 1 & Buffalo River & Extant & Tennessee & 1991.4 & 4 & $19.5 / 4.1$ \\
\hline 2 & Shoal Creek & Reintroduced & Alabama, Tennessee & 1284.9 & 5 & $31.1 / 7.5$ \\
\hline 3 & Little Bear Creek & Extirpated & Alabama & 184.8 & - & $24.6 / 6.7$ \\
\hline 4 & Chickamauga Creek & Extirpated & Georgia, Tennessee & 1205.0 & - & $21.1 / 25.3$ \\
\hline 5 & Whites Creek & Extirpated & Tennessee & 369.4 & - & $7.4 / 7.5$ \\
\hline 6 & Emory River & Extant & Tennessee & 2248.3 & $3,4,5,6$ & $10.6 / 10.3$ \\
\hline 7 & Tellico River & Introduced & North Carolina, Tennessee & 546.9 & 4 & $7.7 / 3.2$ \\
\hline 8 & Citico Creek & Extirpated & Tennessee & 184.8 & - & $0.3 / 1.8$ \\
\hline 9 & Cheoah River & Introduced & North Carolina & 557.8 & 4 & $1.4 / 3.8$ \\
\hline 10 & Abrams Creek & $\begin{array}{l}\text { Extirpated/ } \\
\text { unsuccessful } \\
\text { reintroduction }\end{array}$ & Tennessee & 225.7 & - & $3.7 / 1.7$ \\
\hline 11 & Little Tennessee River & Extant & North Carolina & 1154.7 & 5 & $17.8 / 22.8$ \\
\hline 12 & Tuckasegee River & Extirpated & North Carolina & 1769.1 & - & $2.7 / 5.8$ \\
\hline 13 & French Broad River & Extirpated & North Carolina & 4866.6 & - & $25.2 / 27.1$ \\
\hline 14 & Lower French Broad River & Permitted & Tennessee & 520.4 & 7 & $33.1 / 12.5$ \\
\hline 15 & Lower Holston River & Permitted & Tennessee & 903.3 & 6 & $32.4 / 14.3$ \\
\hline 16 & Powell River & Extirpated & Tennessee, Virginia & 1994.5 & - & $11.1 / 10.1$ \\
\hline 17 & Clinch River & Extirpated & Tennessee, Virginia & 3842.5 & - & $19.6 / 8.0$ \\
\hline 18 & North Fork Holston River & Extant & Tennessee, Virginia & 2488.3 & $2,3,4,6$ & $23.5 / 4.3$ \\
\hline 19 & Middle Fork Holston River & Extant & Tennessee, Virginia & 625.5 & 4 & $40.1 / 9.0$ \\
\hline 20 & South Fork Holston River & Extirpated & Tennessee, Virginia & 1194.6 & - & $25.2 / 27.1$ \\
\hline
\end{tabular}

and 2017 (Fig. 2B). Locations where E. monachus were collected by the TVA were listed as occupied. We assumed the collections detecting C. galactura but not E. monachus represented sufficient sampling effort to conclude the absence of E. monachus because both species have a high degree of co-occurrence, use similar habitats, and are known to hybridize (Burkhead \& Bauer 1983, Etnier \& Starnes 1993, Jenkins \& Burkhead 1993). Some locations designated as absent could have E. monachus present due to their rarity; however, most sites were sampled multiple times between 1986 and 2017 without detection. Therefore, we can reasonably assume they do not occupy absent sites for the purpose of this study. Additionally, most sites were systematically sampled across the species' distribution in the last 10 yr corresponding with contemporary landscape data. This dataset included 237 unique sampling locations, including 36 where E. monachus was present and 201 where E. monachus was considered absent (i.e. only C. galactura was collected).
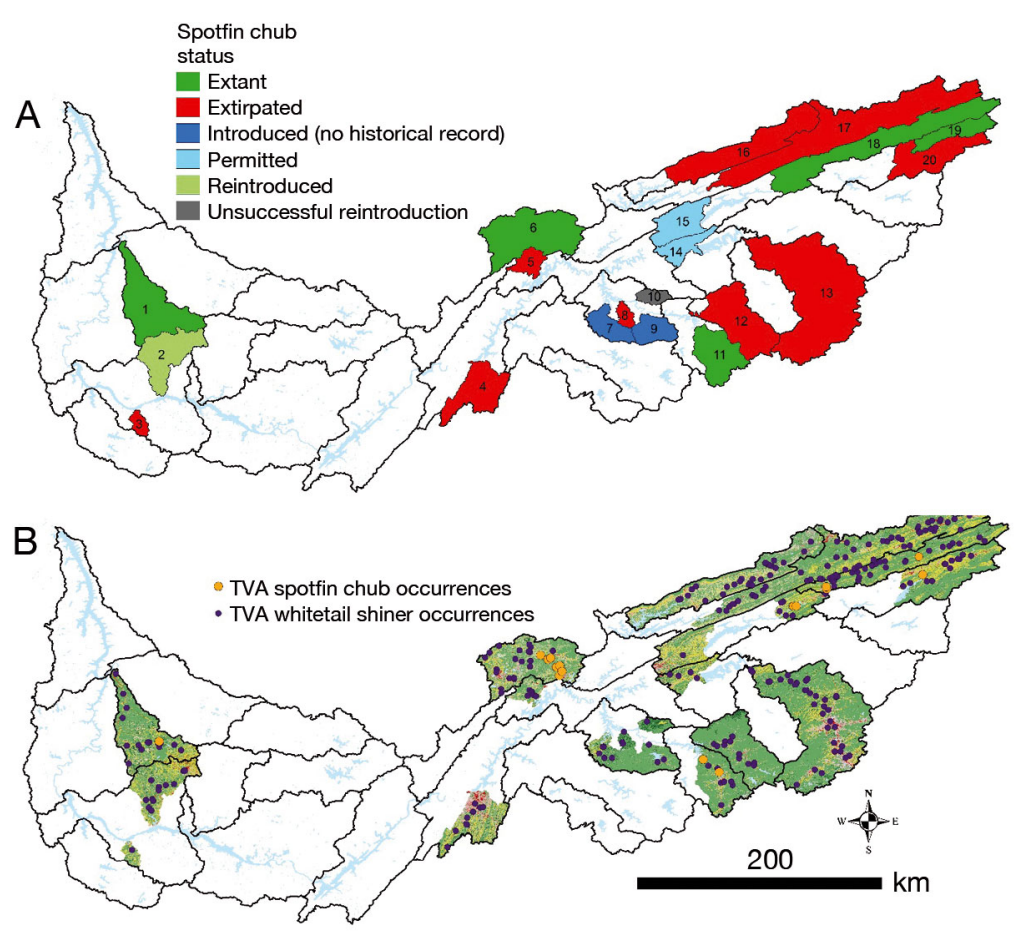

Fig. 2. (A) Status of Erimonax monachus in subcatchments of the Tennessee River Basin throughout their historical distribution. (B) E. monachus and Cyprinella galactura observations from Tennessee Valley Authority (TVA) sampling from 1986 to 2017 overlaying current land use patterns. Green land use signifies forested areas, yellow indicates agricultural land use, and red represents development 


\subsection{Statistical analysis}

We identified stream segments from the NHD that overlapped spatially with the 237 sampling locations using GPS coordinates from the TVA collections. We joined $E$. monachus presence-absence data with the 52 landscape metrics and fit a random forest (RF) classification model to describe E. monachus occurrence (Cutler et al. 2007). For the RF model, E. monachus occurrence ( $1=$ present; $0=$ absent $)$ was the response variable, and the landscape metrics (Table 1) were the predictor variables. We fit the model using the randomForest function from the randomForest package in $\mathrm{R}$, including 2000 trees with 3 variables tried at each split (Liaw \& Wiener 2002). We determined the number of variables tried at each split using the tuneRF function from the randomForest package and addressed class imbalance using the synthetic minority over-sampling technique (SMOTE) method described by Chawla et al. (2002) with the SMOTE function from the DMwR package (Torgo 2010) in $\mathrm{R}$. The resampling with SMOTE improved the imbalanced data $(0=201$ observations; $1=36$ observations) so that 72 observations of each class were created. We assessed model fit to the training data using metrics described by Evans \& Cushman (2009), including out-of-bag (OOB) error rate, sensitivity (i.e. proportion of observed positives correctly predicted), specificity (i.e. proportion of observed absences correctly predicted), and Kappa ([observed accuracy - expected accuracy]/[1 - expected accuracy]; range 0-1). We also tested model significance following the methods of Murphy et al. (2010). We then used 5-fold cross-validation using the rf.crossValidation function from the rfUtilities package (Evans \& Murphy 2018) to assess mean sensitivity, specificity, and Kappa across 5 subsets of the data following the methods described by Evans et al. (2011). Finally, we assessed model sensitivity, specificity, and Kappa when the trained model was used to predict occurrence of $E$. monachus from an independent dataset collected by Russ (2006). Russ (2006) conducted surveys for E. monachus at 57 sites distributed across the Emory River Basin and documented presence or absence of the species at each site (see additional details in Kanno et al. 2012b). We used the confusionMatrix function from the caret package (Kuhn et al. 2019) to assess accuracy (and bootstrapped $95 \%$ CIs), sensitivity, specificity, and Kappa of the model when applied to the independent dataset.

We assessed relative variable importance in the model using the rf.partial.prob function from the
rfUtilities package and created partial dependence plots (PDPs) with overlaid LOWESS regression lines using the methods described by Baruch-Mordo et al. (2013). Variable importance was measured using the metric mean decrease in Gini, which measures the decrease in classification accuracy as variables are excluded from trees. The largest mean decrease in Gini represents the most important variable; thus, the ranking according to Gini, rather than the Gini score itself, gives insight into variable importance. PDPs illustrate the effect of a single predictor variable across its range of observed values while holding all others at their mean (Friedman 2001). We scaled the $y$-axis of PDPs to the probability of E. monachus occurrence using the rf.partial.prob function, which gives both the typical splined PDP plus an overlaid LOWESS regression line with $95 \%$ CIs (Evans et al. 2011). All analyses were conducted in $\mathrm{R}$ version 3.5.2 (R Core Team 2018).

\subsection{Ecological niche projections}

We used our ENM to predict the probability of occurrence of E. monachus for all stream segments within the historical and contemporary range of the species. This approach is useful for evaluating habitats at previously unsampled sites and across broad spatial extents. We used the predict function from the randomForest package to fit model predictions for the probability of occurrence (0-1) to stream segment data across all subcatchments shown in Fig. 2. We first mapped predicted occurrences within the Emory River Basin to illustrate agreement between our ENM and observations by Russ (2006). We then developed predictions for all stream segments within the historical or introduced range of E. monachus in the Tennessee River Basin.

\section{RESULTS}

Our ENM suggested Erimonax monachus distribution is influenced by landscape-level characteristics and alterations. Model performance assessment from the training dataset included a low error rate (OOB error rate $=4.17 \%), 93 \%$ of observed positives correctly predicted (sensitivity $=0.93$ ), $96 \%$ of observed absences correctly predicted (specificity $=0.96$ ), and Kappa $=0.88$, and the model explained a significant level of variation in occurrence $(p<0.0001)$. Five-fold cross-validation results showed mean sensitivity was 0.75 , mean specificity was 1.00 , and mean Kappa was 
Table 3. Ecological niche model performance based on sensitivity, specificity, and Kappa from training data, 5-fold cross-validation, and testing on a dataset (i.e. Russ 2006) not included in model training

\begin{tabular}{|lccc|}
\hline $\begin{array}{l}\text { Performance } \\
\text { metric }\end{array}$ & $\begin{array}{c}\text { Training } \\
\text { data }\end{array}$ & $\begin{array}{c}\text { Five-fold cross- } \\
\text { validation }\end{array}$ & $\begin{array}{c}\text { Russ } \\
(2006)\end{array}$ \\
\hline Sensitivity & 0.93 & 0.75 & 0.92 \\
$\begin{array}{l}\text { Specificity } \\
\text { Kappa }\end{array}$ & 0.96 & 1.00 & 0.88 \\
& 0.88 & 0.87 & 0.71 \\
\hline
\end{tabular}

0.87 (Table 3). When tested on the independent dataset collected by Russ (2006), the ENM sensitivity was 0.92 , specificity was 0.88 , and Kappa was 0.71 . Model accuracy when tested against data from Russ (2006) was $89.1 \%(95 \% \mathrm{CI}=77.8-95.9 \%)$. The 6 most important variables were catchment area, percent of the local catchment covered by pasture land use, road length density in the network catchment, minimum stream channel elevation, stream order, and stream runoff. Among land use and landscape alteration metrics, data compiled at the network catchment scale tended to be more important than the same metrics compiled at the local network catchment scale, pasture land use being the exception (Fig. 3).

PDPs illustrated E. monachus responses to the 6 most important landscape metrics (Fig. 4). Probability of occurrence was highest among stream segments with intermediate-sized $\left(2000-3000 \mathrm{~km}^{2}\right)$ upstream network catchments but fell precipitously in smaller streams (Fig. 4A). Probability of occurrence declined in a linear pattern as the percent of the local catchment covered by pasture land use increased from 0 to $40 \%$, and occurrence remained low when $>40 \%$ of local catchments were covered by pasture land use (Fig. 4B). Probability of occurrence was highest at lower densities of road lengths $(0.3-0.5 \mathrm{~km}$ $\mathrm{km}^{-2}$ ) in the network catchment (Fig. 4C). Probability of occurrence was also greatest at intermediate minimum stream channel elevations $(20000-25000 \mathrm{~cm})$ but declined as elevation increased (Fig. 4D). Stream order was treated as a factor in the analysis, and partial dependence for stream order showed the highest probability of occurrence among stream orders 5 and 6 (Fig. 4E). Probability of occurrence was highest for streams with intermediate levels of modeled runoff (900-1000 mm) but declined as runoff increased to 1200 or declined to 400 (Fig. 4F).

PDPs for the 12 next most important variables showed the probability of $E$. monachus occurrence was greatest among least disturbed streams of intermediate size (Fig. 5). Probability of occurrence was

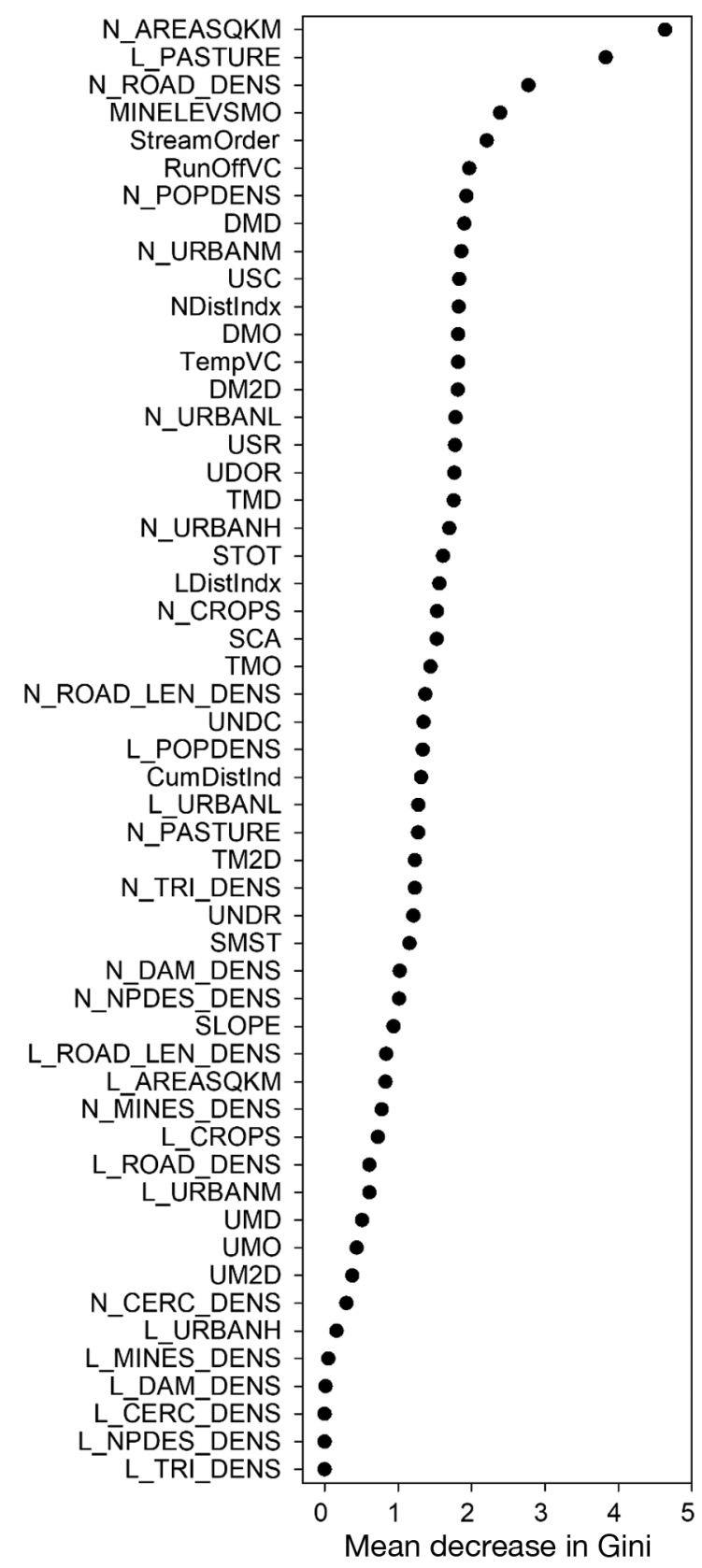

Fig. 3. Variable importance plot of the best-fitting random forest model determining Erimonax monachus occurrence throughout their current distribution

highest among stream segments with low human population density $\left(<40\right.$ people $\left.\mathrm{km}^{-2}\right)$ in the network catchment (Fig. 5A), intermediate densities (0.350.40 dams $100 \mathrm{~km}^{-2}$ ) of downstream mainstem dams (Fig. 5B), intermediate percent medium-intensity urban land use $(0.4-0.5 \%)$ in the network catchment (Fig. 5C), and minimum $\left(<6\right.$ ha $\left.\mathrm{m}^{-1} \mathrm{~km}^{-2}\right)$ upstream reservoir storage per stream network catchment area (Fig. 5D). Probability of occurrence was greatest 
A

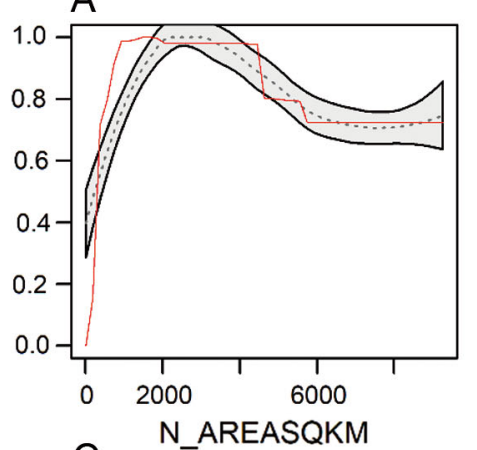

C

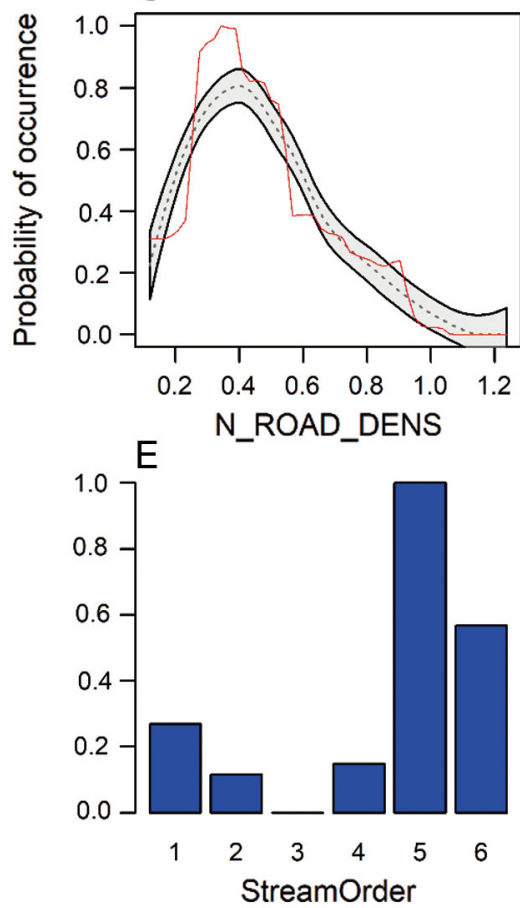

B

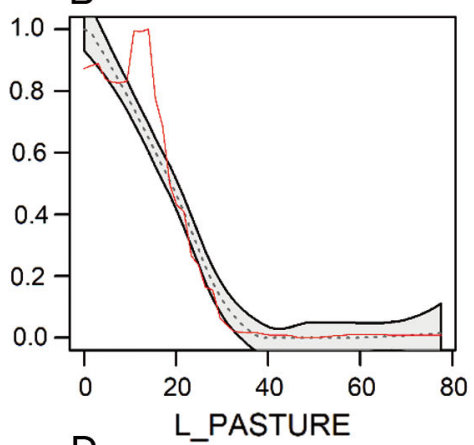

$\mathrm{D}$

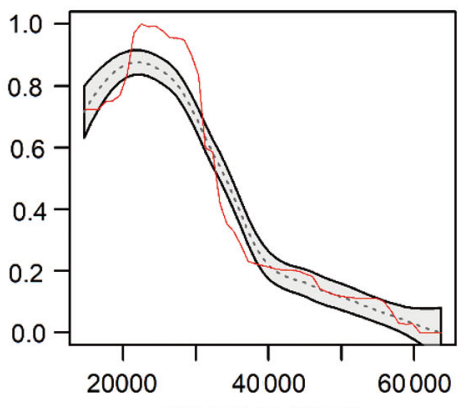

MINELEVSMO

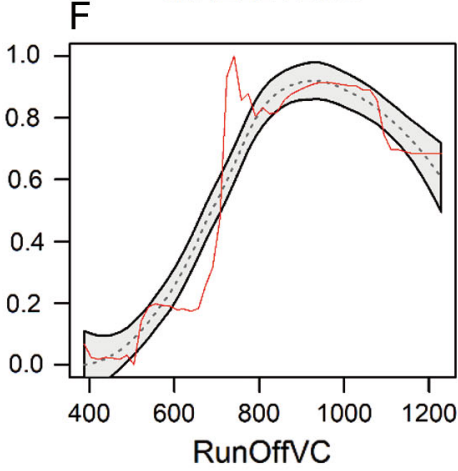

Fig. 4. Partial dependence plots (red lines), overlaid with LOWESS regression curves (black dashed lines) and 95\% CIs (solid black lines, gray filled areas) of the 6 most important variables included in the ecological niche model fit to Erimonax monachus occurrence. See Table 1 for variable descriptions, scales, and units

among stream segments with minimal risk of habitat degradation (Fig. 5E), smaller percentages (3-4\%) of downstream mainstem streams free of dams (Fig. 5F), higher $\left(1350-1400^{\circ} \mathrm{C} \times 100\right)$ annual air temperatures (Fig. 5G), and shorter distances $(50-100 \mathrm{~km})$ to downstream mainstem dams (Fig. 5H). Probability of occurrence was highest among stream segments with lower percentages (4-6\%) of low-intensity urban land use in network catchments (Fig. 5I), minimal $\left(<750\right.$ hectare-meters ${ }^{-1} 100 \mathrm{~km}^{-1}$ ) total upstream reservoir storage volume per stream network length (Fig. 5J), no annual discharge stored in upstream reservoirs (Fig. 5K), and lower (0.25-0.35 dams $100 \mathrm{~km}^{-1}$ ) total mainstem dam density (Fig. 5L).
Projections from the ENM showed strong agreement with the independent test dataset and highlighted current and potential conservation priorities for E. monachus. In the Emory River Basin, probability of occurrence was highest (0.75-1.00) in the lower Emory River where Russ (2006) documented occurrence of the species (Fig. 6). The ENM predicted low probability of occurrence among smaller and higher-elevation streams in the Emory River Basin, the same locations where Russ (2006) did not report occurrence of the species despite widespread search efforts. Across the Tennessee River Basin, E. monachus probability of occurrence was predicted to be $>0.75$ at locations where the species is known to persist, including portions of the Emory, Buffalo, Little Tennessee, North Fork Holston, and Middle Fork Holston rivers (Fig. 7). The ENM also highlighted areas of potential occurrence based on riverscape conditions, including limited portions of the lower Powell River and lower Whites Creek. Elsewhere in the Tennessee River Basin, the ENM predicted large areas of intermediate probabilities of occurrence (0.50-0.74) among stream segments where reintroductions have occurred, including Shoal Creek, the Tellico River, and lower Abrams Creek. The ENM did not predict probability of occurrence $>0.50$ for any segment in the Cheoah River, a location where the species is known to persist as the result of introductions. Predictions from the ENM showed intermediate probability of occurrence (0.50-0.74) for sections of the lower Holston and lower French Broad rivers, 2 locations permitted for reintroduction attempts.

\section{DISCUSSION}

The Tennessee River Basin was altered extensively after 1900, resulting in 744 known dams with $>38.7$ million $\mathrm{m}^{3}$ of combined storage capacity. Much of the natural channel in the Tennessee River and its major tributaries is inundated by large reservoirs or chan- 

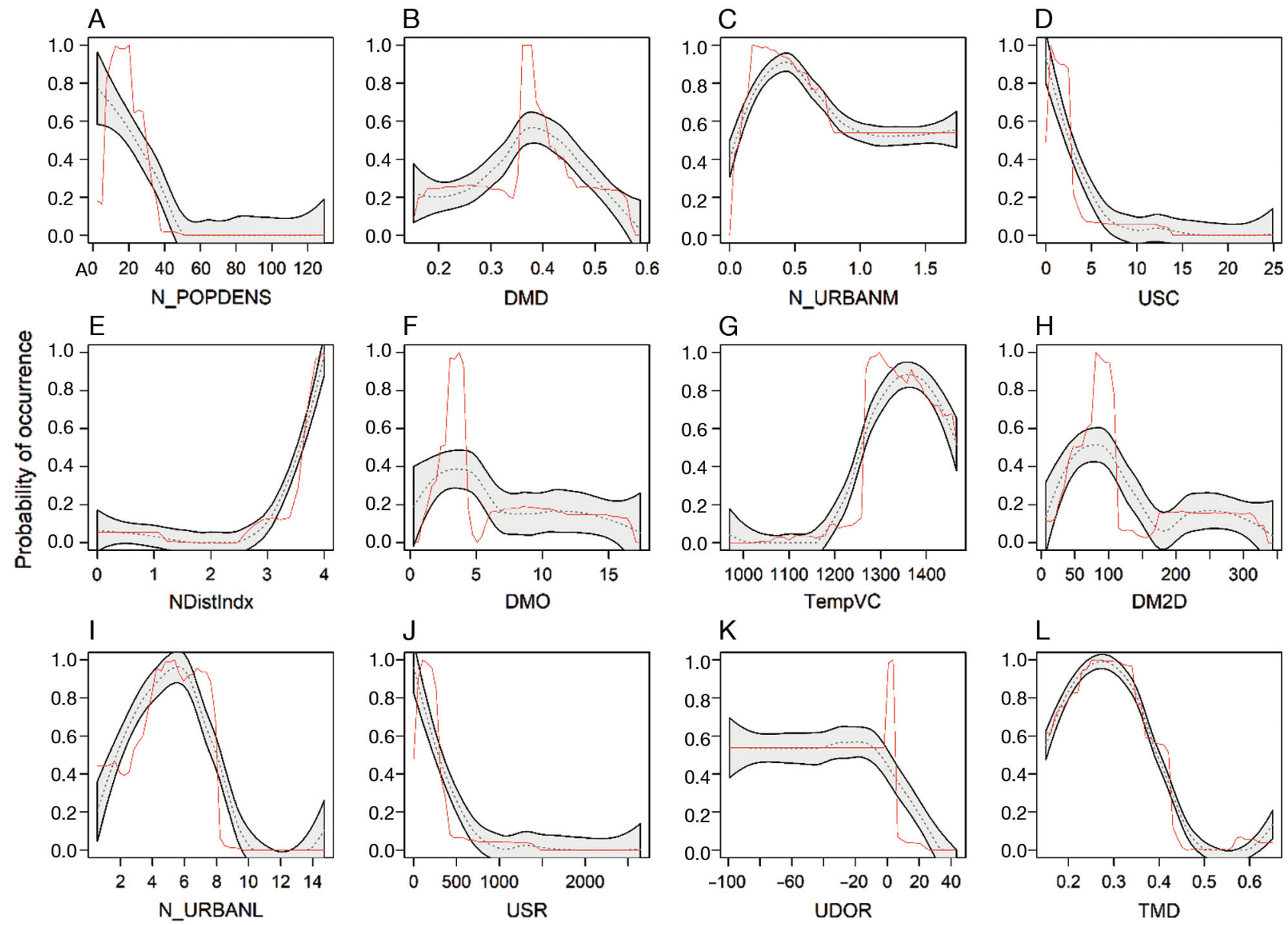

Fig. 5. Partial dependence plots (red lines), overlaid with LOWESS regression curves (black dashed lines) and $95 \%$ CIs (solid black lines, gray filled areas) of the 12 intermediate-importance variables included in the ecological niche model fit to Erimonax monachus occurrence. See Table 1 for variable descriptions, scales, and units

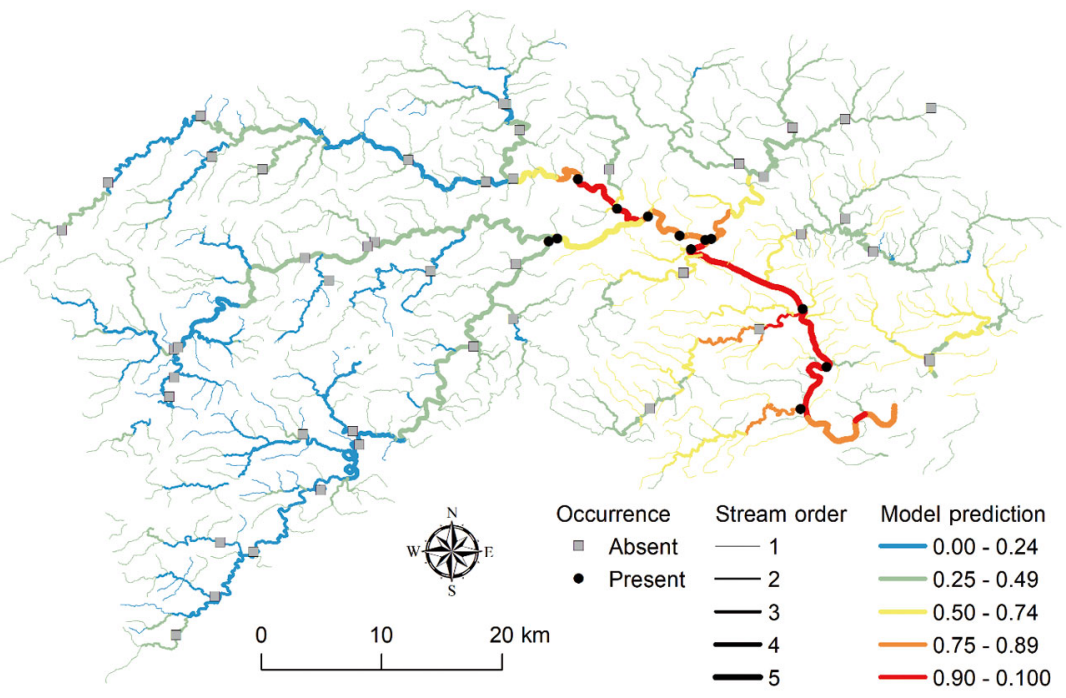

Fig. 6. Emory River basin, Tennessee, USA, illustrating validation of the ecological niche model (ENM) developed for Erimonax monachus. Stream lines are colored according to the probability of occurrence from the ENM and are sized according to stream order. Points from Russ (2006) show the presence (black circles) or absence (gray boxes) of E. monachus at 57 sampling sites nelized, resulting in profound effects on the aquatic fauna (Neves \& Angermeier 1990, Etnier \& Starnes 1991, Knight et al. 2012). Many fish species have thrived because of the altered hydrography and river morphology, whereas others have been extirpated from the basin (McManamay et al. 2013). Other species that require medium-sized streams, such as Erimonax monachus, have persisted in localized and highly fragmented populations (Etnier 1997). We found modeled E. monachus occurrences were greatest in streams with network catchment drainage areas 300 to $1000 \mathrm{~km}^{2}$, stream order 5 or 6 , and elevations 1000 to $3500 \mathrm{~cm}$. These remnants of medium-sized streams are isolated by reservoirs that are likely impassable by E. monachus, and the 


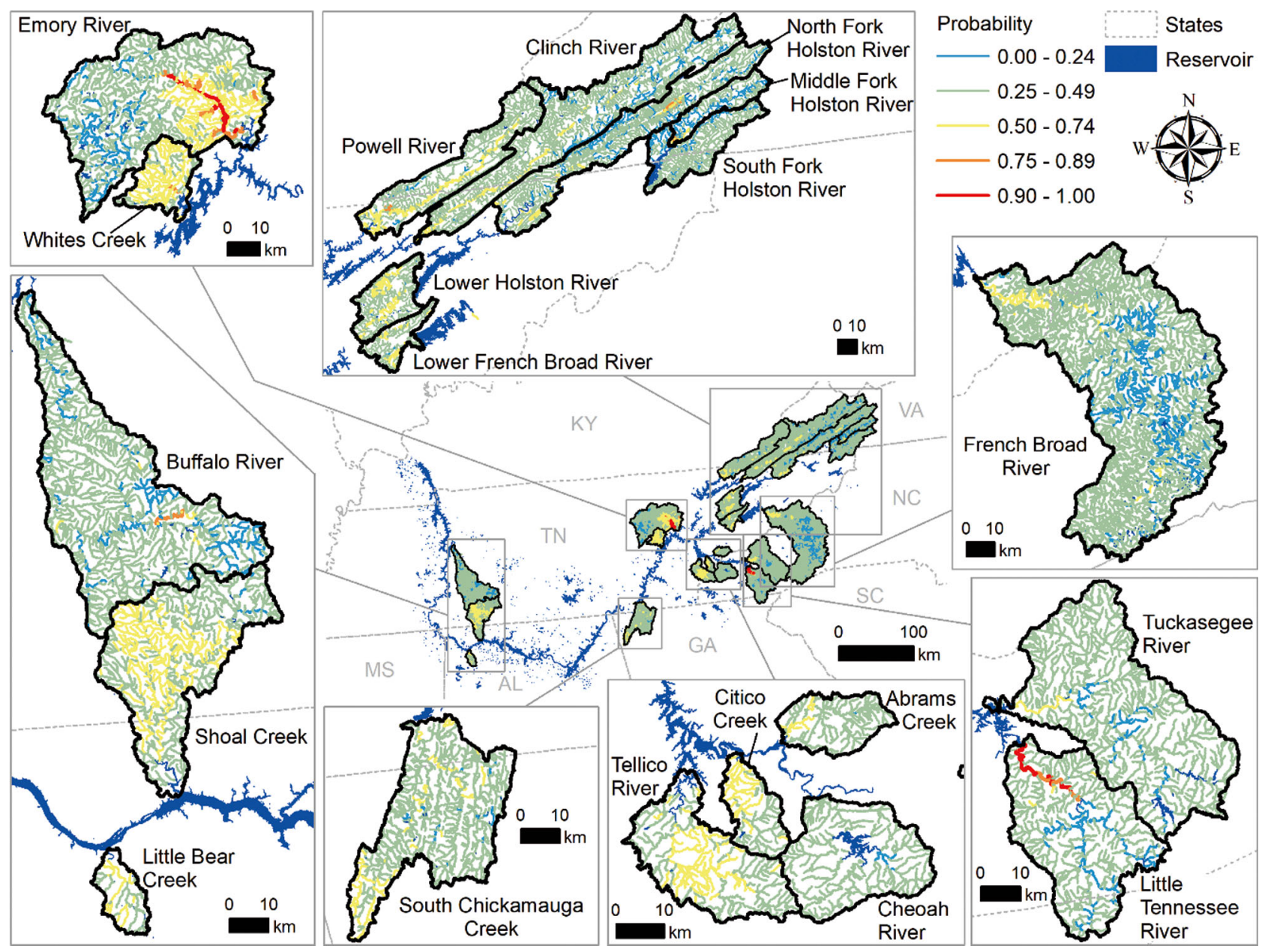

Fig. 7. Probability of Erimonax monachus occurrence throughout the historical distribution of the species based on landscapelevel suitability identified by ecological niche modelling

species is relegated to isolated patches of habitat that are differentially affected by human alterations to landscapes (Jenkins \& Burkhead 1984). Conservation of the species requires maintenance of existing occupied habitats and identifying where habitats appropriate for reintroductions might exist (USFWS 1983).

We found that stream network connectivity metrics, both natural and altered, were a strong predictor of E. monachus occurrence. The current distribution of the species now exists in the largest remaining streams on the margins of large reservoirs, including stream segments within 100 river $\mathrm{km}$ of downstream dams (DM2D $<100 \mathrm{~km}$ ), where $<4 \%$ of downstream mainstem river habitat is free of dams (DMO $<4 \%)$, and where the density of downstream dams is high (DMD > 0.35 dam km${ }^{-1}$ ). We suspect that these connectivity patterns are not reflective of E. monachus dependence on reservoirs but rather that habitats historically used by the species are now inundated under reservoirs and populations are relegated to the remaining large stream habitats persisting upstream of reservoirs. The entire historical distribution of the species is unknown, but the current disjunct distribution does provide anecdotal evidence of a much larger historical distribution (Etnier \& Starnes 1993). Although individuals did not likely traverse the entire length of the Tennessee River within a single lifetime, it is possible that individuals moved between adjacent catchments to interbreed and maintain genetic diversity and connectivity. Such dispersal opportunities are now thwarted by large dams and impoundments, meaning that smaller and isolated populations must contend with environmental fluctuations without the benefit of metapopulation dynamics (e.g. Roberts et al. 2013). A result is the strong potential for rare disturbance events, either natural or anthropogenic, to cause localized extirpations in a manner consistent with the ecological 
ratcheting hypothesis (ERH). The ERH posits that disturbances with temporal extents that exceed the generation time of affected species and result in population extirpation are reinforced by habitat fragmentation that prevents recolonization once the disturbance subsides (Perkin et al. 2015b). Fragmentation through impoundment and altered hydrologic regimes has played a role in the current distribution of E. monachus (Jenkins \& Burkhead 1984). However, fragmented populations persisted for over $60 \mathrm{yr}$ in some isolated reaches but not in other reaches with similar habitat connectivity. If historical extirpations were due to acute stressors or chronic perturbations that are now alleviated, these systems may represent potential reintroduction sites necessary to fulfill the objectives of the recovery plan (USFWS 1983). For this reason, it is critical to consider interactions among multiple forms of habitat alteration and how they might jointly influence distribution.

We found evidence that human alterations to landscapes beyond connectivity affect the distribution of E. monachus. Changes to land use are among the primary causes for native species loss, especially in the historically forested southeastern USA (Warren et al. 2000). Agricultural land uses in particular are problematic because they alter sediment deposition regimes and contribute to loss of habitat through siltation in streams (Allan et al. 1997, Burcher et al. 2007). Previous works at fine spatial scales documented silt substrate avoidance by E. monachus (Kanno et al. $2012 \mathrm{~b}$ ), and we found that broad-scale distributions were negatively influenced by the same agricultural land uses that contribute to siltation. In particular, we found that E. monachus occurrence was greatest among stream segments with $<10 \%$ pasture land use and $<0.1 \%$ cultivated crop land use in the upstream network catchment and $<20 \%$ pasture land use in the upstream local catchment. Furthermore, other land use alterations that promote altered runoff and sediment regimes were influential, evident through the higher occurrence of E. monachus in segments with $<0.60$ road $\mathrm{km}^{-2}$ in the upstream network catchment. These anthropogenic alterations each represent composites of the habitat disturbance index developed by Esselman et al. (2011), and we found that E. monachus occurrence was greatest among stream habitats with low habitat disturbance in the upstream network catchment (NDistIndx > 3.75). Unfortunately, land uses such as pasture and crop that are most likely to result in degraded water and habitat quality tend to occur in lower elevations and around larger rivers, the same habitats naturally used by E. monachus. Evidence from previous works suggests historical land uses likely influence the contemporary distribution of E. monachus, though additional historical land use data are necessary to understand how (Harding et al. 1998). The inescapable influence of 'the ghosts of riverscapes past' was likely a contributor to the incongruence between predictions and observations of E. monachus in our model (Perkin et al. 2013, 2015b, 2019).

Furthermore, our study did not include direct measures of water quality that likely influence distribution of E. monachus (e.g. Hitt et al. 2016), nor did we address the encroachment of an invasive species (Ridgway \& Bettoli 2017). Future research should address the influences of these parameters as broadscale datasets become available.

Our framework is useful for conservation planning within fragmented and human-affected riverscapes. The ENM we developed highlighted known habitat hotspots for E. monachus, including the Emory River and the Little Tennessee River. However, our model also highlighted appropriate habitats where successful reintroductions have occurred, including Shoal Creek and the Tellico River. Three additional catchments, Whites Creek, the Tuckasegee River, and the French Broad River, were identified as having a high probability of harboring E. monachus if reintroductions were to occur. These systems should be surveyed for the best in-stream habitat to maximize the success of any future reintroductions (Kanno et al. $2012 b)$. This point is particularly relevant because failed reintroductions are costly from the perspective of funds, effort, and the demise of individuals placed into insufficient habitats. For example, Gibbs (2009) showed that reintroduction of E. monachus into lower Abrams Creek was unsuccessful despite highquality habitats and extensive stocking efforts (Shute et al. 2005). In our ENM, the probability of occurrence for E. monachus in lower Abrams Creek was 0.30 to 0.49 , suggesting a low probability of successful reintroduction. Therefore, factors other than coarse-scale habitat alone influence the success of reintroductions, as recently discussed by Malone et al. (2018). Additionally, historical records from smaller catchments $\left(<300 \mathrm{~km}^{2}\right)$, such as Abrams, Citico, and Little Bear creeks, may represent temporary use by the species or individuals uncharacteristically present when sampling occurred (e.g. migrants to sink habitats). As a second example, our model predicted low probability of occurrence (0.30-0.49) for E. monachus in the Cheoah River, a location where a reintroduced population has persisted for at least 8 yr (S. Fraley pers. comm.). Thus, we suggest that ENM is only one aspect of reintroduction planning 
that should take place, a point recently made by Malone et al. (2018). Local conditions and in-stream characteristics are known to influence the occurrence of E. monachus but have only been extensively studied in 2 of the 5 extant populations (Kanno et al. 2012b). Our model provides some insight into other locations that might be more thoroughly investigated to assess (re)introduction potential.

Our analytical framework is applicable to other rare species, especially those with unknown or patchy historical distributions. Availability of broad-scale sampling datasets is increasing (Troia \& McManamay 2017), which allows for exploratory analyses of species distributions such as those presented herein (Huang \& Frimpong 2015). Knowledge of landscapelevel drivers of current fish distributions can be used to identify additional sites where sampling could be targeted or reintroductions proposed. Of particular interest to natural resource managers is the incorporation of scale in conservation planning (Wellemeyer et al. 2019). We used habitat alteration metrics measured at 2 scales, local catchment and network catchment, and found landscape alterations measured at the network catchment scale correlated more strongly with E. monachus distribution. In these instances where network catchment scale alterations are most influential, broad-scale conservation initiatives such as NFCAs can be established. Our work supports recent calls for catchment-level management practices, including maintaining riparian buffers and restoring connectivity, to sustain suitable habitat and provide long-term population viability for rare and sensitive species (Gido et al. 2016, Wipfli \& Richardson 2016).

ORCID: Joshua S. Perkin: 0000-0002-1409-2706; Josey L. Ridgway: 0000-0003-4157-7255

Acknowledgements. We thank Jeff Simmons with the TVA for providing sampling data for this project. We also appreciate feedback regarding initial analyses and interpretations from Johnathan Davis, Steve Fraley, and Jeff Simmons during the 2017 Southeastern Fishes Council meeting. We thank Amanda Rosenberger for a valuable critique and improvement of the manuscript. The comments and suggestions of the editor and anonymous reviewers greatly improved this publication, and we sincerely appreciate their time and effort. The Department of Biology at Tennessee Technological University, the Department of Wildlife and Fisheries Sciences at Texas A\&M University, and the USDA National Institute of Food and Agriculture (HATCH Project 1017538) provided funding for this project. Any use of trade, firm, or product names is for descriptive purposes only and does not imply endorsement by the US government.

\section{LITERATURE CITED}

Abell R, Thieme ML, Revenga C, Bryer M and others (2008) Freshwater ecoregions of the world: a new map of biogeographic units for freshwater biodiversity conservation. Bioscience 58:403-414

* Allan JD, Erickson D, Fay J (1997) The influence of catchment land use on stream integrity across multiple spatial scales. Freshw Biol 37:149-161

Angermeier PL (1995) Ecological attributes of extinctionprone species: loss of freshwater fishes of Virginia. Conserv Biol 9:143-158

Baruch-Mordo S, Evans JS, Severson JP, Naugle DE and others (2013) Saving sage-grouse from the trees: a proactive solution to reducing a key threat to a candidate species. Biol Conserv 167:233-241

* Benke AC (1990) A perspective on America's vanishing streams. J N Am Benthol Soc 9:77-88

Burcher CL, Valett HM, Benfield EF (2007) The land cover cascade: relationships coupling land and water. Ecology 88:228-242

B Burkhead NM, Bauer BH (1983) An intergeneric cyprinid hybrid, Hybopsis monacha $\times$ Notropis galacturus, from the Tennessee River drainage. Copeia 1983:1074-1077

* Chawla NV, Bowyer KW, Hall LO, Kegelmeyer WP (2002) SMOTE: synthetic minority over-sampling technique. J Artif Intel Res 16:321-357

Closs GP, Angermeier PL, Darwall WRT, Balcombe SR (2016) Why are freshwater fish so threatened? In: Closs GP, Krkosek M, Olden JD (eds) Conservation of freshwater fishes. Cambridge University Press, Cambridge, p 37-75

Cole DA, Landers PB (1995) Indirect effects of recreation on wildlife. In: Knight RL, Gutzwiller KJ (eds) Wildlife recreationists: coexistence through management and research. Island Press, Washington, DC, p 183-202

Cooke SJ, Paukert C, Hogan Z (2012) Endangered river fish: factors hindering conservation and restoration. Endang Species Res 17:179-191

Cooper AR, Infante DM (2017) Dam metrics representing stream fragmentation and flow alteration for the conterminous United States linked to the NHDPLUSV1. US Geological Survey data release. https://doi.org/doi: 10.5066/F7FN14C5 (accessed on 4 Jun 2018)

* Craven SW, Peterson JT, Freeman MC, Kwak TJ, Irwin E (2010) Modeling the relations between flow regime components, species traits, and spawning success of fishes in warmwater streams. Environ Manage 46:181-194

Cutler DR, Edwards TC, Beard KH, Cutler A, Hess KT, Gibson J, Lawler JJ (2007) Random forests for classification in ecology. Ecology 88:2783-2792

* Dudgeon D, Arthington AH, Gessner MO, Kawabata Z and others (2006) Freshwater biodiversity: importance, threats, status and conservation challenges. Biol Rev Camb Philos Soc 81:163-182

ESRI (Environmental Systems Research Institute) (2015) ArcView 10.4.1. Environmental Systems Research Institute, Redlands, CA

Esselman PC, Infante DM, Wang L, Taylor WW and others (2011) National Fish Habitat Action Plan (NFHAP) 2010 HCI scores and human disturbance data (linked to the NHDPLUSV1) for Southeast Aquatic Resource Partnership. National Fish Habitat Partnership Data System. http://dx.doi.org/doi:10.5066/F75X26Z8 (accessed on 4 Jun 2018) 
Etnier DA (1997) Jeopardized southeastern freshwater fishes: a search for causes. In: Benz GW, Collins DE (eds) Aquatic fauna in peril: the southeastern perspective. Special Publication 1, Southeast Aquatic Research Institute. Lenz Design \& Communications, Decatur, GA, p 87-104

Etnier DA, Starnes WC (1991) An analysis of Tennessee's jeopardized fish taxa. J Tenn Acad Sci 66:129-133

Etnier DA, Starnes WC (1993) The fishes of Tennessee. University of Tennessee Press, Knoxville, TN

Evans JS, Cushman SA (2009) Gradient modeling of conifer species using random forests. Landsc Ecol 24:673-683

Evans JS, Murphy MA (2018) rfUtilities. R package version 2.1-3. https://cran.r-project.org/package =rfUtilities (accessed on 27 Jul 2019)

Evans JS, Murphy MA, Holden ZA, Cushman SA (2011) Modeling species distribution and change using Random Forest. In: Drew CA, Huettmann F, Wiersma Y (eds) Predictive modeling in landscape ecology. Springer, New York, NY, p 139-159

Fausch KD, Torgersen CE, Baxter CV, Li HW (2002) Landscapes to riverscapes: bridging the gap between research and conservation of stream fishes. Bioscience 52:483-498

Federal Register (1977) Endangered and threatened wildlife and plants; final threatened status and critical habitat for five species of southeastern fishes. Federal Register 42: 45526-45530

Federal Register (2002) Endangered and threatened wildlife and plants; establishment of nonessential experimental population status and reintroduction of four fishes in the Tellico River. Federal Register 67:52420-52428

Federal Register (2005) Endangered and threatened wildlife and plants; establishment of a nonessential experimental population for two fishes (boulder darter and spotfin chub) in Shoal Creek, Tennessee and Alabama. Federal Register 70:17916-17927

Federal Register (2007) Endangered and threatened wildlife and plants; establishment of a nonessential experimental population for 15 freshwater mussels, 1 freshwater snail, and 5 fishes in the lower French Broad River and in the lower Holston River, Tennessee. Federal Register 72 : 52434-52461

Friedman JH (2001) Greedy function approximation: a gradient boosting machine. Ann Stat 29:1189-1232

Gibbs WK (2009) Current status of the threatened spotfin chub (Erimonax monachus) and the endangered duskytail darter (Etheostoma percnurum) in Abrams Creek, Great Smoky Mountains National Park. MS thesis, Tennessee Technological University, Cookeville, TN

Gido KB, Whitney JE, Perkin JS, Turner TF (2016) Fragmentation, connectivity, and species persistence in freshwater ecosystems. In: Closs G, Krkosek M, Olden J (eds) Conservation of freshwater fishes. Cambridge University Press, Cambridge, p 292-323

*Harding JS, Benfield EF, Bolstad PV, Helfman GS, Jones EBD (1998) Stream biodiversity: the ghost of land use past. Proc Natl Acad Sci USA 95:14843-14847

Hitt NP, Floyd M, Compton M, McDonald K (2016) Threshold responses of blackside dace (Chrosomus cumberlandensis) and Kentucky arrow darter (Etheostoma spilotum) to stream conductivity. Southeast Nat 15:41-61

Huang J, Frimpong EA (2015) Using historical atlas data to develop high-resolution distribution models of freshwater fishes. PLOS ONE 10:e0129995

Jenkins RE, Burkhead NM (1984) Description, biology, and distribution of the spotfin chub, Hybopsis monacha, a threatened cyprinid fish of the Tennessee River drainage. Bull Ala Mus Nat Hist 8:1-30

Jenkins RE, Burkhead NM (1993) Freshwater fishes of Virginia. American Fisheries Society, Bethesda, MD

Kanno Y, Russ WT, Sutherland CJ, Cook SB (2012a) Prioritizing aquatic conservation areas using spatial patterns and partitioning of fish community diversity in a near natural temperate basin. Aquat Conserv 22:799-812

Kanno Y, Schmidt CU, Cook SB, Mattingly HT (2012b) Variation in microhabitat use of the threatened spotfin chub (Erimonax monachus) among stream sites and seasons. Ecol Freshwat Fish 21:363-374

Knight RR, Gain WS, Wolfe WJ (2012) Modelling ecological flow regime: an example from the Tennessee and Cumberland River basins. Ecohydrology 5:613-627

Kuhn M, Wing J, Weston S, Williams A and others (2019) caret: Classification and regression training. $\mathrm{R}$ package version 6.0-84. https://cran.r-project.org/package=caret (accessed on 27 Jul 2019)

Liaw A, Wiener M (2002) Classification and regression by randomForest. R News 2:18-22

* Liermann CR, Nilsson C, Robertson J, Ng RY (2012) Implications of dam obstruction for global freshwater fish diversity. Bioscience 62:539-548

Kytle DA, Poff NL (2004) Adaptation to natural flow regimes. Trends Ecol Evol 19:94-100

Malone EW, Perkin JS, Leckie BM, Kulp MA, Hurt CR, Walker DM (2018) Which species, how many, and from where: integrating habitat suitability, population genomics, and abundance estimates into species reintroduction planning. Glob Change Biol 24:3729-3748

McKay L, Bondelid T, Dewald T, Johnston J, Moore R, Rea A (2012) NHDPlus Version 2: user guide. USEPA Office of Water, Washington, DC

McManamay RA, Orth DJ, Dolloff CA, Mathews DC (2013) Application of the ELOHA framework to regulated rivers in the upper Tennessee River Basin: a case study. Environ Manage 51:1210-1235

Miller RR (1972) Threatened freshwater fishes of the United States. Trans Am Fish Soc 101:239-252

*Murphy MA, Evans JS, Storfer A (2010) Quantifying Bufo boreas connectivity in Yellowstone National Park with landscape genetics. Ecology 91:252-261

*Neves RJ, Angermeier PL (1990) Habitat alteration and its effects on native fishes in the upper Tennessee River system, east-central USA. J Fish Biol 37:45-52

Olden JD (2016) Challenges and opportunities for fish conservation in dam-impacted waters. In: Closs G, Krkosek M, Olden J (eds) Conservation of freshwater fishes. Cambridge University Press, Cambridge, p 107-148

Olden JD, Naiman RJ (2010) Incorporating thermal regimes into environmental flows assessments: modifying dam operations to restore freshwater ecosystem integrity. Freshw Biol 55:86-107

Ostroff A, Wieferich D, Cooper A, Infante D (2013) National anthropogenic barrier dataset (NABD). National Fish Habitat Partnership Data System. https://www.science base.gov (accessed on 4 Jun 2018)

* Perkin JS, Shattuck ZR, Gerken JE, Bonner TH (2013) Fragmentation and drought legacy correlate with distribution of burrhead chub in subtropical streams of North America. Trans Am Fish Soc 142:1287-1298

* Perkin JS, Gido KB, Cooper AR, Turner TF, Osborne MJ, Johnson ER, Mayes KB (2015a) Fragmentation and de- 
watering transform Great Plains stream fish communities. Ecol Monogr 85:73-92

Perkin JS, Gido KB, Costigan KH, Daniels MD, Johnson ER (2015b) Fragmentation and drying ratchet down Great Plains stream fish diversity. Aquat Conserv 25:639-655

Perkin JS, Knorp NE, Boersig TC, Gebhard AE, Hix LA, Johnson TC (2016) Life history theory predicts long-term fish assemblage response to stream impoundment. Can J Fish Aquat Sci 74:228-239

Perkin JS, Murphy SP, Murray CM, Gibbs WK, Gebhard AE (2019) If you build it, they will go: a case study of stream fish diversity loss in an urbanizing riverscape. Aquat Conserv 29:623-638

Perkin JS, Wellmeyer JC, Fore JD (2019) Multiscale fish assemblage distribution models to guide riverscape conservation planning. In: Hughes RM, Infante DM, Wang L, Chen $K$, Tera BF (eds) Advances in understanding landscape influences on freshwater habitats and biological assemblages. Am Fish Soc Symp 90, Bethesda, MD, p 409-440

Peterson AT, Soberón J (2012) Species distribution modeling and ecological niche modeling: getting the concepts right. Nat Conserv 10:102-107

Petts GE (1986) Water quality characteristics of regulated rivers. Prog Phys Geogr 10:492-516

Poff NL, Allan JD, Bain MB, Karr JR and others (1997) The natural flow regime. Bioscience 47:769-784

R Core Team (2018). R: a language and environment for statistical computing. R Foundation for Statistical Computing, Vienna. www.R-project.org/

Richter BD, Braun DP, Mendelson MA, Master LL (1997) Threats to imperiled freshwater fauna. Conserv Biol 11: 1081-1093

Ridgway JL, Bettoli PW (2017) Distribution, age structure, and growth of bigheaded carps in the lower Tennessee and Cumberland rivers. Southeast Nat 16:426-442

Roberts JH, Angermeier PL, Hallerman EM (2013) Distance, dams and drift: What structures populations of an endangered, benthic stream fish? Freshw Biol 58:2050-2064

Russ WT (2006) Current distribution and seasonal habitat use of the threatened spotfin chub in the Emory River watershed. MS thesis, Tennessee Technological University, Cookeville, TN

Shute JR, Rakes PL, Shute PW (2005) Reintroduction of four imperiled fishes in Abrams Creek, Tennessee. Southeast Nat 4:93-110

Starnes WC, Etnier DA (1986) Drainage evolution and fish biogeography of the Tennessee and Cumberland rivers drainage realm. In: Hocutt CH, Wiley EO (eds) The zoogeography of North American freshwater fishes. John

Editorial responsibility: Eduardo Martins,

Vancouver, British Columbia, Canada
Wiley \& Sons, New York, NY, p 325-361

Strahler, AN (1957) Quantitative analysis of watershed geomorphology. Eos, Trans Am Geophys Union 38:913-920

Strayer DL, Dudgeon D (2010) Freshwater biodiversity conservation: recent progress and future challenges. J N Am Benthol Soc 29:344-358

* Sutherland AB, Meyers JL, Gardiner EP (2002) Effects of land cover on sediment regime and fish assemblage structures in four southern Appalachian streams. Freshw Biol 47:1791-1805

Toplovich A (2017) Tennessee River system. In: The Tennessee encyclopedia of history and culture, v.1.0. Tennessee Historical Society, Nashville, TN. https:// tennesseeencyclopedia.net/entries/tennessee-river-system/ (accessed on 17 Nov 2017)

Torgo L (2010) Data mining with R, learning with case studies. Chapman \& Hall/CRC, Boca Raton, FL

* Troia MJ, McManamay RA (2017) Completeness and coverage of open access freshwater fish distribution data in the United States. Divers Distrib 23:1482-1498

USFWS (US Fish and Wildlife Service) (1983) Spotfin chub recovery plan. US Fish and Wildlife Service, Atlanta, GA

Vitousek PM, Mooney HA, Lubchenco J, Melillo JM (1997) Human domination of Earth's ecosystems. Science 277: 494-499

WWarren ML, Burr BM (1994) Status of freshwater fishes of the United States: overview of an imperiled fauna. Fisheries (Bethesda, MD) 19:6-18

Warren ML, Burr BM, Walsh SJ, Bart HL Jr and others (2000) Diversity, distribution and conservation status of the native freshwater fishes of the southern United States. Fisheries (Bethesda, MD) 25:7-29

*Wellemeyer JC, Perkin JS, Jameson ML, Costigan KH, Waters R (2019) Hierarchy theory reveals multiscale predictors of Arkansas darter (Etheostoma cragini) abundance in a Great Plains riverscape. Freshw Biol 64:659-670

Wenger SJ (2008) Use of surrogates to predict the stressor response of imperiled species. Conserv Biol 22:1564-1571

White D, Johnston K, Miller M (2005) Ohio River basin. In: Benke AC, Cushing CE (eds) Rivers of North America. Elsevier Academic Press, Burlington, MA, p 375-424

*Williams JE, Williams RN, Thurow RF, Elwell L and others (2011) Native fish conservation areas: a vision for largescale conservation of native fish communities. Fisheries (Bethesda, MD) 36:267-277

Wipfli MS, Richardson JS (2016) Riparian management and the conservation of stream ecosystems and fishes. In: Closs G, Krkosek M, Olden J (eds) Conservation of freshwater fishes. Cambridge University Press, Cambridge, p 270-291

Submitted: May 10, 2019; Accepted: August 15, 2019

Proofs received from author(s): October 17, 2019 